\title{
Removal of reactive dye from aqueous solution using coagulation-flocculation coupled with adsorption on papaya leaf
}

\author{
M.Z.B. Mukhlish ${ }^{1}$, M.M.R. Khan ${ }^{1,2 *}$, A.R. Islam ${ }^{1}$ and A.N.M.S. Akanda ${ }^{1}$ \\ ${ }^{1}$ Department of Chemical Engineering and Polymer Science, \\ Shahjalal University of Science and Technology. Sylhet 3114, Bangladesh. \\ ${ }^{2}$ Faculty of Chemical and Natural Resources Engineering, Universiti Malaysia Pahang, \\ 26300 Gambang, Kuantan, Pahang, Malaysia \\ *E-mail:mrkhancep@yahoo.com, mrkhan@ump.edu.my \\ Phone: +609-5492872; Fax : +609-5492889
}

\begin{abstract}
Attempts were made to investigate the effectiveness of a combined process of coagulation-flocculation and adsorption for the removal of reactive dye (Reactive Red 3BS) from aqueous solution. The effluent obtained from the coagulation-flocculation process was the raw solution for the second step of the coupling process, i.e. adsorption. The coagulation-flocculation process and the adsorption method were also studied individually. The optimum $\mathrm{pH}$ and the optimum dosages of alum and calcium oxide for the coagulation-flocculation process were determined. Aluminium sulphate (alum), calcium oxide and papaya leaf were used as the coagulant, coagulant aid and adsorbent, respectively. Complete dye removal from raw solution having a concentration of $100 \mathrm{mg}$ $\mathrm{L}^{-1}$ could be achieved by using $300 \mathrm{mg} \mathrm{L}^{-1}$ of alum, $80 \mathrm{mg} \mathrm{L}^{-1}$ of calcium oxide and 0.20 $\mathrm{g}$ of papaya leaf adsorbent. Adsorption tests showed that papaya leaf could be used as a potential adsorbent for the removal of Reactive Red 3BS from aqueous solution. The maximum sorption capacities of papaya leaf in the case of sorption from pretreated solution and pure solution were $50.23 \mathrm{mg} \mathrm{g}^{-1}$ and $21 \mathrm{mg} \mathrm{g}^{-1}$, respectively. The combined coagulation-flocculation/adsorption process may be a useful treatment technique for wastewater contaminated with reactive dye.
\end{abstract}

Keywords: Adsorption isotherm; combined study; Reactive Red 3BS; coagulation.

\section{INTRODUCTION}

The textile industries extensively use water, chemicals and dyes for finishing and dyeing operations. Bangladesh, having thousands of textile industries mostly situated near big cities, produces a huge amount of dye-contaminated wastewater which drains away into the rivers. The aquatic environment of the rivers (e.g. Buriganga, Karnafully, etc.) is in the worst situation. Most textile dyes are synthetic compounds with complex aromatic molecular structures, which make them resistant to light, heat and oxidizing agents, nonbiodegradable and toxic to life, with carcinogenic and mutagenic effects $[1,2]$ and up to $50 \%$ of reactive dyes are lost through hydrolysis during the dyeing process. In order to treat wastewater containing reactive dyes, a trial and error experimental run for the selection of a treatment technique is usually followed. Several treatment processes such as ozonation [3], ultrafiltration[4], photocatalytic degradation [5, 6], adsorption [7, 8], and coagulation-flocculation [9] have been widely employed to remove dyes from wastewater. It is hard to mention a single process that is capable of adequate treatment, 
mainly due to the complex nature of the effluent. Combined treatment techniques can be used to overcome the deficiency of the single process. To obtain treated water with reliable quality, several treatment techniques such as ozonation coupled with coagulation [10], coagulation-flocculation coupled with a membrane process [11], and chemical coagulation coupled with ion exchange [12] are being used. The coagulation-flocculation process followed by an adsorption technique may be used to achieve the desired water quality in the most economical way.

Coagulation is a classical method for the treatment of wastewater. Activated carbon is used as adsorbent [13-16] in some combined coagulation-flocculation/ adsorption treatment systems. However, activated carbon is cost prohibitive and neither the regeneration nor the disposal of used carbon is straightforward. There are many low-cost adsorbents such as banana peel, orange peel, bagasse pith, rice husk, sawdust, coir fibres, and periwinkle shell ash [17-19] which are abundantly available in nature. In the present work, low cost papaya leaf (Carica papaya L.) powder has been studied as an adsorbent to remove Reactive Red 3BS from aqueous solution. Papaya (Carica papaya L.) is a tropical and subtropical crop. Bangladesh produces thousands of tonnes of papaya fruit and papaya leaf has no potential use in this country. Moreover, papaya leaf (PL) is biodegradable and abundantly available year round and disposable without any need for regeneration. The dyes used in the textile industries include several structure varieties such as acidic, reactive, basic, disperse, azo, diazo, anthraquinone-based and metal complex dyes [20]. Reactive dyes are the most problematic compared to other forms of dye [21]. Papaya leaf has been used as adsorbent for the removal of a basic dye (methylene blue) [22], but no study has ever been conducted to use papaya leaf as adsorbent for the removal of reactive dye. The purpose of this work was to study the coagulationflocculation process in combination with the adsorption method for the removal of Reactive Red 3BS from aqueous solution. Alum and calcium oxide were used as coagulant and coagulant aid, respectively. The optimum $\mathrm{pH}$ and the optimum dosages of alum and calcium oxide for the coagulation-flocculation process were determined. Batch adsorption experiments were carried out to reveal the potentiality of papaya leaf for the removal of reactive dye. The equilibrium data of the sorption studies were fitted to an equilibrium model to elucidate the sorption mechanism. The effluent obtained from the coagulation-flocculation process was treated with the adsorption method to reveal the performance of the combined method.

\section{MATERIALS AND METHODS}

\section{Reagents and Adsorbent}

All chemicals used in the study were of analytical grade and used without further purification. Alum: $\mathrm{Al}_{2}\left(\mathrm{SO}_{4}\right)_{3} .18 \mathrm{H}_{2} \mathrm{O}$, calcium oxide $(\mathrm{CaO})$, hydrochloric acid and sodium hydroxide were purchased from MERCK, Germany. Reactive Red 3BS was obtained from Clariant, India. Papaya leaf (PL) was collected from local papaya trees in the Sylhet area, thoroughly washed several times to remove dirt, air-dried and then dried in an oven at $105^{\circ} \mathrm{C}$. The dried papaya leaf was ground and the powder thus obtained was used as adsorbent. The particle size of the adsorbent samples used for the experiments was in the range of $0.11-0.25 \mathrm{~mm}$. The stock solution of $1000 \mathrm{mg} \mathrm{L}^{-1}$ of dye was prepared in distilled water and working solutions were obtained by appropriate dilution. The concentration of the dye in the solution was measured using a UV spectrophotometer (UV-1601, Shimadzu, Japan) at the wavelength of $540.5 \mathrm{~nm}$, where the maximum absorbance was observed. The $\mathrm{pH}$ of $100 \mathrm{mg} / \mathrm{L}$ dye solution was recorded as 5.5. With 
the addition of papaya leaf adsorbent, the $\mathrm{pH}$ of the dye solution spontaneously increases. For $\mathrm{pH}$ adjustment, sodium hydroxide $(\mathrm{NaOH}) 0.1 \mathrm{M}$ or hydrochloric acid $(\mathrm{HCl}) 0.1 \mathrm{M}$ was used.

\section{Coagulation-flocculation Studies}

In order to obtain optimal process parameters $(\mathrm{pH}$, dosages of coagulant and coagulant aid) for the coagulation-flocculation process, experiments were conducted using conventional jar test apparatus that contained six jars. Each of the six jars was filled with $1 \mathrm{~L}$ of dye solution and dosed with coagulant. Coagulant aid was also added along with alum to the dye solution when required. After the chemical addition, the solution was stirred rapidly $(300 \mathrm{rpm})$ for $1 \mathrm{~min}$ to ensure complete dispersion of the chemicals, followed by slow mixing (100 rpm) for $60 \mathrm{~min}$ to aid in the formation of flocs, and then allowed to settle for $20 \mathrm{~min}$. At the end of the sedimentation period, the dye concentration of the supernatant was measured. During the study of the effect of the $\mathrm{pH}$ on the coagulation-flocculation process, the $\mathrm{pH}$ of the initial dye solution was adjusted in the range of $2-10$ before being subjected to the jar test.

\section{Adsorption Studies}

Batch sorption experiments were performed by mixing $0.2 \mathrm{~g}$ of papaya leaf (PL) sorbent with $0.1 \mathrm{~L}$ aqueous solution of reactive dye with various initial concentrations in $250 \mathrm{~mL}$ conical flasks placed on a flask shaker (Stuart Scientific Co. Ltd., Model SF1, UK). The $\mathrm{pH}$ of the solution after addition of $0.2 \mathrm{~g}$ of adsorbent in $0.1 \mathrm{~L}$ dye solution was recorded as 10.5. After the flasks had been shaken at $500 \mathrm{rpm}$ for $24 \mathrm{~h}$, the solution was centrifuged for the separation of solid particles and the final concentration of dye in the solution was determined. The adsorption density, defined as the amount of dye adsorbed per unit weight of adsorbent at equilibrium $q_{e}$ (mg dye/g adsorbent), was calculated by Eq. (1):

$$
q_{e}=\frac{\left(C_{0}-C e\right) V}{W}
$$

where $C_{0}$ and $C_{e}$ are the initial and equilibrium concentrations of dye in the solution (mg $\mathrm{L}^{-1}$ ), respectively; $V$ is the volume of the solution (L) and $W$ is the mass of dry adsorbent used $(\mathrm{g})$.

Some experiments were also conducted using varying amounts of the adsorbent (2.0-6.0 $\left.\mathrm{g} \mathrm{L}^{-1}\right)$ at $\mathrm{pH} 10.5$.

\section{Adsorption Isotherm}

The analysis of isotherm data is useful for design purposes. In the present study the equilibrium sorption data were treated with the Langmuir isotherm. The Langmuir model [23] is valid for monolayer sorption onto a surface with a finite number of similar active sites. The Langmuir isotherm can be represented by Eq. (2):

$$
\frac{1}{q_{e}}=\frac{1}{K q_{\alpha} C_{e}}+\frac{1}{q_{\alpha}}
$$

where $q_{\alpha}$ is the maximum adsorption capacity (mg dye/g adsorbent); $C_{e}$ is the equilibrium concentration of dye $\left(\mathrm{mg} \mathrm{L}^{-1}\right)$ in the solution and $K\left(\mathrm{~L} \mathrm{mg}^{-1}\right)$ is the adsorption equilibrium 
constant. The values of $q_{\alpha}$ and $K$ were calculated from the slope and intercept of the linear plot of $1 / q_{\mathrm{e}}$ versus $1 / \mathrm{C}_{\mathrm{e}}$.

\section{Combined Study}

Coagulation was performed as the main treatment process followed by adsorption onto papaya leaf adsorbent. The first step, i.e. coagulation, was carried out at $\mathrm{pH}$ 5.5. The residue obtained from coagulation was the raw solution for the second step of the coupled process, i.e. adsorption. After addition of papaya leaf adsorbent, the $\mathrm{pH}$ of the solution was raised to 10.5 and the adsorption step was carried out at $\mathrm{pH} 10.5$.

\section{RESULTS AND DISCUSSION}

\section{Coagulation-flocculation Studies}

Insufficient dosage or overdosing of coagulant and coagulant aid would result in poor performance of the coagulation-flocculation process. It was crucial to determine the optimum $\mathrm{pH}$, and the dosage of coagulant (alum) and coagulant aid (calcium oxide) in order to minimize the dosing cost and obtain the optimum performance in the treatment.

\section{Optimum dosage of coagulant}

Chemical coagulation using alum as a coagulant was shown to be highly effective in the removal of Reactive Red 3BS. The effect of dosage was analysed at $\mathrm{pH} 5.5$ (natural $\mathrm{pH}$ of the dye solution) and the initial dye concentration of $100 \mathrm{mg} \mathrm{L}^{-1}$, varying the dosage of coagulant from $50 \mathrm{mg} / \mathrm{L}^{-1}$ to $800 \mathrm{mg} \mathrm{L}^{-1}$. The dye removal as a function of coagulant concentration is shown in Figure 1. The removal efficiency for the dye increased with the coagulant dose up to a certain dose. On further increase in the coagulant dose, the removal efficiency decreased gradually. It was observed that to attain good dye removal (higher than $50 \%$ ) the alum dose should be in the range of $250 \mathrm{mg} \mathrm{L}^{-1}$ to $450 \mathrm{mg} \mathrm{L}^{-1}$. The optimum alum dose was $300 \mathrm{mg} \mathrm{L}^{-1}$, which provided the maximum colour removal efficiency of $58.47 \%$.

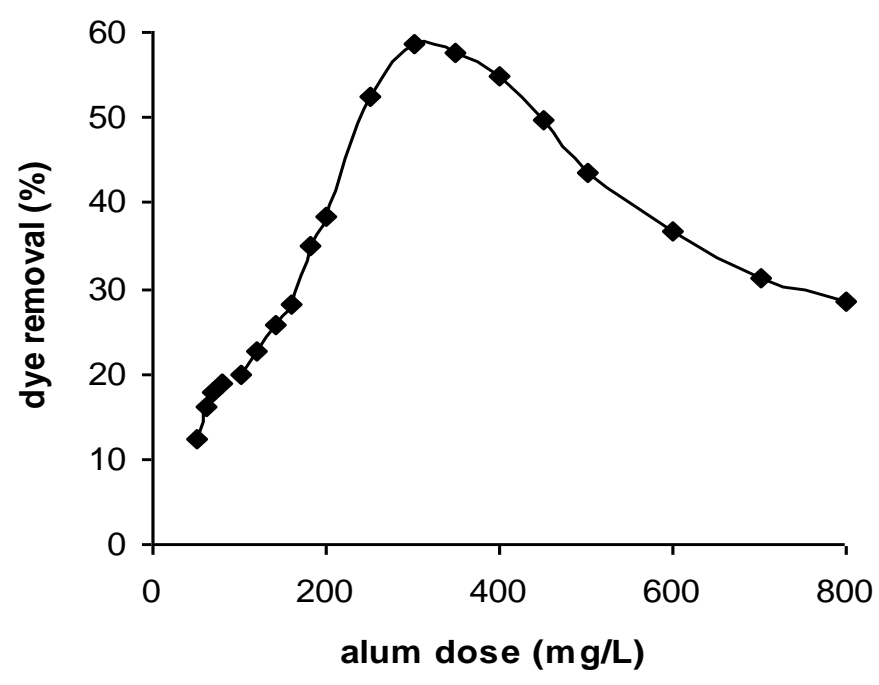

Figure 1. Effect of alum dosage for the removal of Reactive Red 3BS in the coagulation-flocculation process. (Initial concentration, $\mathrm{Co}=100 \mathrm{mg} \mathrm{L}^{-1}$; initial solution $\mathrm{pH}=5.5$; temperature, $\mathrm{T}=25 \pm 1{ }^{\circ} \mathrm{C}$; dosages of alum $=50-800 \mathrm{mg} \mathrm{L}^{-1}$ ). 
The amount of aluminium ions in the coagulant determines the amount of destabilization of the dye. Overdosing with coagulant can result in charge reversal and restabilization of the suspension. As the alum dose alters the amount of flocs formed and their settling tendency, the removal efficiency of dye decreased with the quantity of coagulant above or below the optimum dose [13].

\section{Optimum dosage of coagulant aid}

Lime imparts alkalinity to the dye solution and provides a medium suitable for the formation of the insoluble $\mathrm{Al}(\mathrm{OH})_{3}$ precipitate. In order to determine the effect of coagulant aid $(\mathrm{CaO})$ on the coagulation-flocculation process, experiments were conducted at the predetermined optimum alum dose $\left(300 \mathrm{mg} \mathrm{L}^{-1}\right)$, varying the dosage of $\mathrm{CaO}$ from $40 \mathrm{mg} \mathrm{L}^{-1}$ to $200 \mathrm{mg} \mathrm{L}^{-1}$. The percentage removal of Reactive Red 3BS at different coagulant doses is presented in Figure 2.

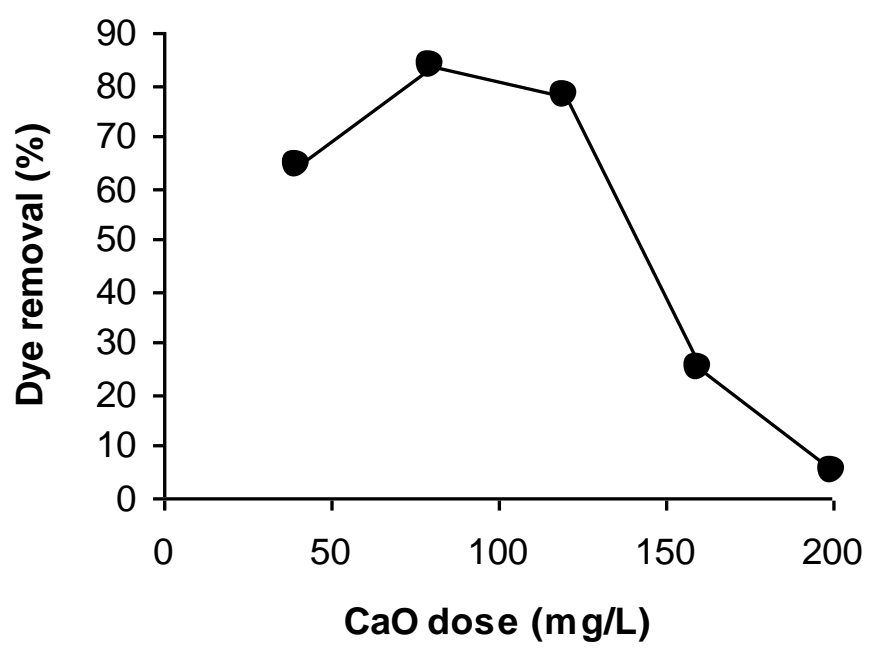

Figure 2. Effect of coagulant aid $(\mathrm{CaO})$ dosage for the removal of Reactive Red 3BS in the coagulation-flocculation process. $\left(\mathrm{Co}=100 \mathrm{mg} \mathrm{L}^{-1} ; \mathrm{pH}=5.5 ; \mathrm{T}=25 \pm 1{ }^{\circ} \mathrm{C}\right.$; dosages of $\mathrm{CaO}=40-200 \mathrm{mg} \mathrm{L}^{-1}$; dosage of alum $\left.=300 \mathrm{mg} \mathrm{L}^{-1}\right)$.

The dye removal efficiency increased with increasing $\mathrm{CaO}$ dose up to $80 \mathrm{mg} \mathrm{L}^{-1}$. Further increase in the coagulant dose decreased the percentage removal of dye. The percentage removal of dye reached a maximum (83.64) with the use of $80 \mathrm{mg} \mathrm{L}^{-1} \mathrm{CaO}$ and then decreased to 77.93 when the dose of $\mathrm{CaO}$ was increased to $120 \mathrm{mg} \mathrm{L}^{-1}$. Further addition of $\mathrm{CaO}$ above $120 \mathrm{mg} \mathrm{L}^{-1}$ caused a sudden drop in the removal efficiency to $4.96 \%$. This may be due to the fact that lime solution acts as a $\mathrm{pH}$ controller and, with increase in $\mathrm{CaO}$ dose, the $\mathrm{pH}$ as well as the alkalinity of the solution also increases. The higher the $\mathrm{pH}$, the higher the negative charges had by the solution and the more aluminium coagulants are needed to neutralize and precipitate the charged species [24]. In addition, the demand for alum increases with increase of alkalinity. The optimal dose of alum also increases with increasing alkalinity [25]. Consequently, at constant alum dose, increase of the $\mathrm{CaO}$ dose above the optimum amount causes the decrease of dye removal efficiency. Furlan et al. [13] carried out studies with aluminium chloride $\left(\mathrm{AlCl}_{3} \cdot 6 \mathrm{H}_{2} \mathrm{O}\right)$ as coagulant and sodium carbonate $\left(\mathrm{Na}_{2} \mathrm{CO}_{3}\right)$ as coagulant aid and reported that the maximum dye removal efficiencies for Reactive Black 5 and Reactive Orange16 were observed with the dosages of 200 and $250 \mathrm{mg} \mathrm{L}^{-1}$ of coagulant and 110 and $140 \mathrm{mg} \mathrm{L}^{-1}$ 
of coagulant aid, respectively. The nature of the curves was also similar to that obtained in the present study.

\section{Optimum $\mathrm{pH}$ for coagulation}

Figure 3 depicts the effect of the initial dye solution $\mathrm{pH}$ (2 to 10) on the dye removal in the coagulation-flocculation process. The coagulation effect was strongly dependent on the $\mathrm{pH}$ of the dye solution. The conditions used were: dosage of alum $=300 \mathrm{mg} \mathrm{L}^{-1}$; dosage of $\mathrm{CaO}$ of $80 \mathrm{mg} \mathrm{L}^{-1}$; initial dye solution concentration of $100 \mathrm{mg} \mathrm{L}^{-1}$; and temperature of $25 \pm 1{ }^{\circ} \mathrm{C}$. As shown in Figure 3, the best performance in terms of colour removal was achieved in the range of $\mathrm{pH} 4-8$ and this corresponds to the region where positively charged $\mathrm{Al}(\mathrm{OH})^{2+}$ and $\mathrm{Al}_{2}(\mathrm{OH})_{2}{ }^{+}$, and insoluble $\mathrm{Al}(\mathrm{OH})_{3}$ species prevailed. Cations are able to conduct primarily charge neutralization, as Reactive Red 3BS dye molecules are negatively charged in aqueous solution, while insoluble species favour coagulation by sweep precipitation. It can be noticed that the dye removal efficiency at very low and high $\mathrm{pH}$ was very poor, only $3.6 \%$ and $29.5 \%$ at $\mathrm{pH} 2$ and 10 respectively. As $\mathrm{pH} 5.5$ is the $\mathrm{pH}$ of normal dye solution, it is taken to be the optimum $\mathrm{pH}$ at which $83.64 \%$ dye removal is observed. Colour removal can be attributed to the fact that within the optimum $\mathrm{pH}$ range, dye particles retain net negative charges which facilitate the performance of cationic coagulant. On the higher and lower sides of the optimum $\mathrm{pH}$ range, the removal efficiency of dye was reduced, possibly due to the formation of soluble forms of aluminium ions [26].

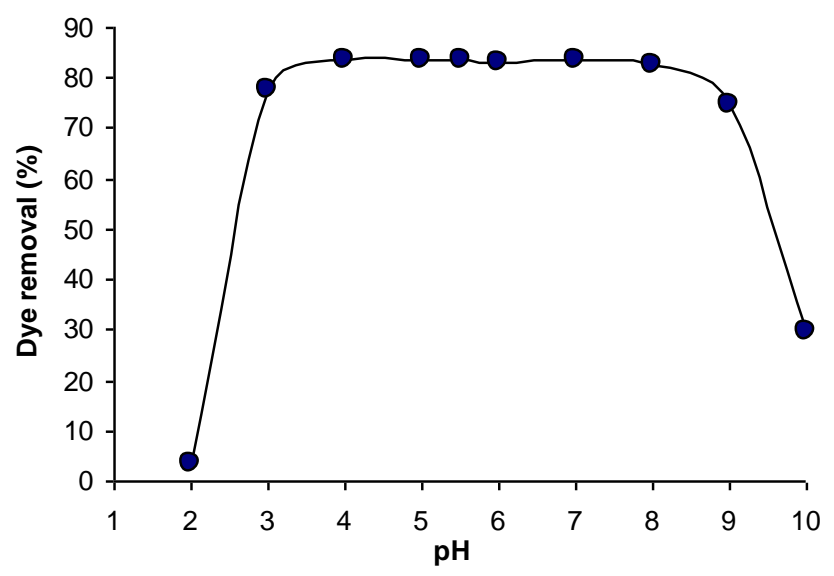

Figure 3. Effect of $\mathrm{pH}$ on coagulation-flocculation process.

\section{Adsorption Studies Using Pure Dye Solution}

\section{Adsorption isotherm}

The equilibrium data of Reactive Red 3BS sorption onto papaya leaf adsorbent was treated with the Langmuir isotherm and is presented in Figure 4. The sorption equilibrium data fitted well to the Langmuir isotherm equation with a correlation coefficient value of 0.981. The calculated isotherm parameters are shown in Table 1, from which it is observed that the maximum sorption capacity of papaya leaf adsorbent for Reactive Red 3BS was $21 \mathrm{mg} \mathrm{g}^{-1}$. The separation factor $\left(R_{L}\right)$ can be estimated to assess whether or not the adsorption process will be favorable [27][27] from Eq. (3):

$$
R_{L}=\frac{1}{1+K C_{o}}
$$


where $C_{o}$ is the highest initial concentration of the adsorbate and $K$ is the Langmuir constant. The parameter $R_{L}$ predicts that the type of isotherm could be irreversible $\left(R_{L}=0\right)$, favorable $\left(0<R_{L}<1\right)$ or unfavorable $\left(R_{L}>1\right)$.

The value of $R_{L}$ has been determined to be 0.088 for the highest initial dye concentration of $120 \mathrm{mg} / \mathrm{L}$, indicating that the adsorption process is favorable.

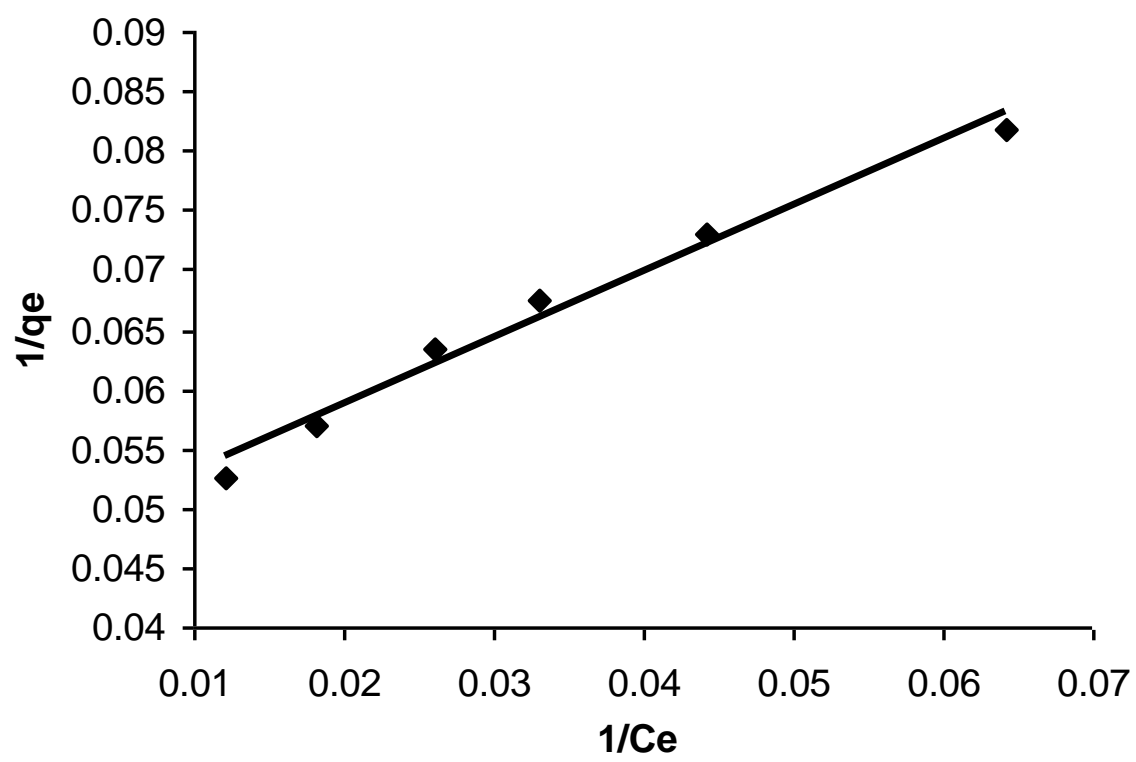

Figure 4. Langmuir isotherm for the adsorption of Reactive Red 3BS from pure solution onto papaya leaf powder. $(\mathrm{W}=0.2 \mathrm{~g}$; volume of solution $=0.1 \mathrm{~L} ; \mathrm{pH}=10.5$; $\mathrm{t}=24 \mathrm{hr} ; \mathrm{T}=25 \pm 1^{\circ} \mathrm{C}$; shaking speed $=500 \mathrm{osc} / \mathrm{min}$ ).

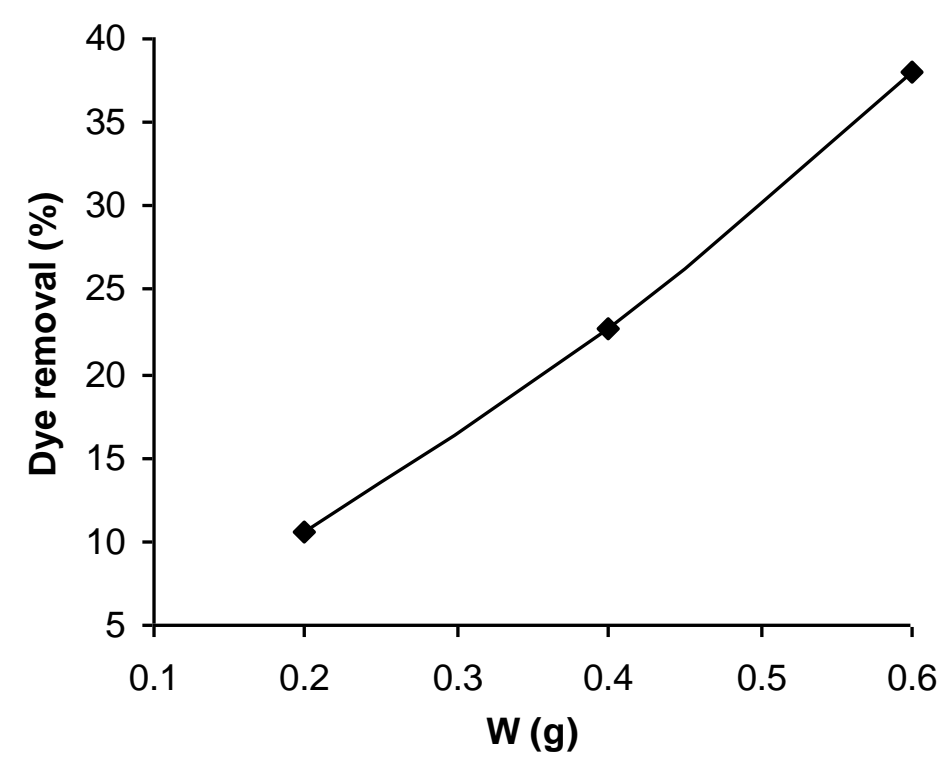

Figure 5. Effect of adsorbent dosage on the removal of Reactive Red 3BS by papaya leaf powder. $\left(\mathrm{Co}=100 \mathrm{mg} \mathrm{L}^{-1} ; \mathrm{W}=0.2,0.4\right.$ and $0.6 \mathrm{~g}$; volume of solution $=0.1 \mathrm{~L}$; $\mathrm{pH}=10.5 ; \mathrm{t}=200 \mathrm{~min} ; \mathrm{T}=25 \pm 1^{\circ} \mathrm{C}$; shaking speed $\left.=500 \mathrm{osc} / \mathrm{min}\right)$. 


\section{Effect of adsorbent dosage}

A range of $0.2-0.6 \mathrm{~g}$ of the adsorbent was mixed with $0.1 \mathrm{~L}$ of dye solution and the effect of the adsorbent dosage on the removal of Reactive Red 3BS was studied at fixed $\mathrm{pH}$ (10.5), temperature $\left(25 \pm 1^{\circ} \mathrm{C}\right)$ and adsorbate concentration $\left(100 \mathrm{mg} \mathrm{L}^{-1}\right)$. The percentage removal of dye from aqueous solution for different adsorbent dosages is shown in Figure 5. From the figure it is observed that the percentage colour removal estimated after 200 min increased from 10.59 to 38.07 for an increase in adsorbent mass from $0.2 \mathrm{~g}$ to $0.6 \mathrm{~g}$. This might be due to the fact that the number of active sites capable of dye adsorption increased with increase in the adsorbent dosage.

\section{Coupling of Coagulation-flocculation Process and Adsorption Method}

In the coupling study, the coagulation step was conducted at the optimum parameters that were estimated from the separate coagulation study and the conditions used were: dosage of alum of $300 \mathrm{mg} \mathrm{L}^{-1}$; dosage of $\mathrm{CaO}$ of $80 \mathrm{mg} \mathrm{L}^{-1}$; $\mathrm{pH}$ value of 5.5; and initial dye concentration range of $100-350 \mathrm{mg} \mathrm{L}^{-1}$. The residue obtained from the coagulationflocculation process was the raw solution for the second step of the coupling process, i.e. adsorption. The adsorption equilibrium tests were performed with $0.20 \mathrm{~g}$ of papaya leaf adsorbent and $100 \mathrm{ml}$ of pretreated effluent (effluent after coagulation-flocculation process) having concentrations in the range of $17.5-67.65 \mathrm{mg} \mathrm{L}^{-1}$. It was obtained that the colour of $100 \mathrm{mg} \mathrm{L}^{-1}$ Reactive Red 3BS dye solution had been removed completely by the combined treatment method. Similar results were observed from some other combined treatment methods. Lin and Liu [28] employed a continuous process of combined ozonation and chemical coagulation for treatment of textile wastewater from dyeing plants. It was shown that complete decolorization of the wastewater was achieved by ozonation, whilst chemical coagulation was responsible for removing the dissolved organic compounds and solid suspensions, resulting in a high percentage of COD (chemical oxygen demand) removal. Riera-Torres et al. [29] used a coagulationflocculation process in combination with a nanofiltration technique for textile wastewater treatment. It was found that over $98 \%$ of colour removal could be achieved using this combined process. Lee et al. [15] chose a hybrid process with combined coagulationadsorption-membrane treatment system and observed that the combined process had a great potential application for complete reactive dye removal and production of highquality treated water. Lin and Chen [12] used a combined treatment process consisting of the Fenton process, chemical coagulation and ion exchange, which revealed that the combined chemical treatment methods were capable of elevating the water quality of the treated wastewater effluent to the reuse standard of the textile industry.

The experimental equilibrium data of the sorption study were treated with the Langmuir isotherm model as shown in Figure 6. The calculated Langmuir parameters as well as the corresponding linear correlation coefficient value are presented in Table 1. It can be seen from Table 1 that the maximum monolayer adsorption capacity of papaya leaf for the sorption of dye from pretreated solution was $50.23 \mathrm{mg} \mathrm{g}^{-1}$. In the case of sorption from pure dye solution, the maximum sorption capacity was found to be $21 \mathrm{mg}$ $\mathrm{g}^{-1}$. It is evident that while running the coupled process of coagulation and adsorption, the capacity of the adsorbent becomes higher compared to that observed in adsorption from pure dye solution. Coagulation before adsorption is suitable as it provides the solution a status that causes an enhanced adsorption. The dye solution resulting from the coagulation-flocculation process may contain an amount of alum- or lime-derived 
compound that changes the solution chemistry of the effluent and provides a better adsorption capacity.

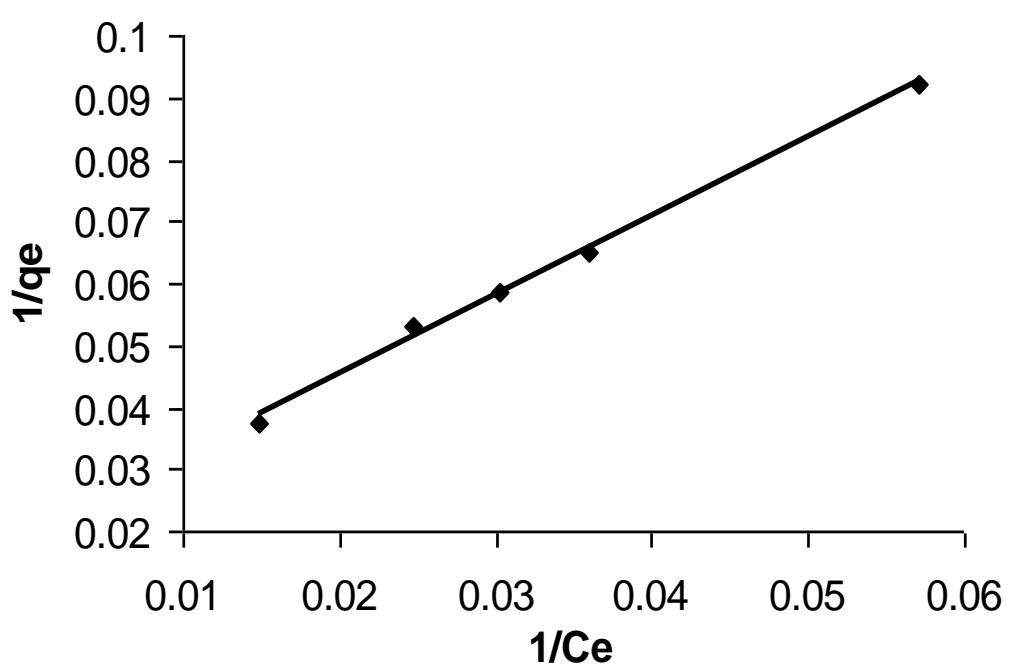

Figure 6. Langmuir isotherm for the adsorption of Reactive Red 3BS from treated solution onto papaya leaf powder. $(\mathrm{W}=0.2 \mathrm{~g}$; volume of solution $=0.1 \mathrm{~L}$; $\mathrm{pH}=10.5 ; \mathrm{t}=24 \mathrm{hr} ; \mathrm{T}=25 \pm 1^{\circ} \mathrm{C}$; shaking speed $\left.=500 \mathrm{osc} / \mathrm{min}\right)$.

Table 1. Comparison of model parameters obtained from sorption experiments using pure dye solution and coagulation-flocculation treated dye solution.

\begin{tabular}{|l|l|l|l|}
\hline \multirow{2}{*}{ Type of solution } & \multicolumn{3}{|c|}{ Langmuir isotherm parameters } \\
\cline { 2 - 4 } & $q_{\alpha}\left(\mathrm{mg} \mathrm{g}^{-1}\right)$ & $K\left(\mathrm{~L} \mathrm{mg}^{-1}\right)$ & $R^{2}$ \\
\hline Treated dye solution & 50.23 & 0.01565 & 0.996 \\
\hline Pure dye solution & 21.00 & 0.08555 & 0.981 \\
\hline
\end{tabular}

\section{CONCLUSIONS}

The coagulation-flocculation/adsorption process is suitable for the treatment of aqueous solutions containing reactive dye. The coagulation-flocculation process revealed that alum requires a certain dose of $\mathrm{CaO}$ for good flocculation performance. The optimum dosages of coagulant (alum) and coagulant aid (calcium oxide) were 300 and $80 \mathrm{mg} \mathrm{L}^{-1}$, respectively for $100 \mathrm{mg} \mathrm{L}^{-1}$ of dye solution. About $58.47 \%$ dye removal was achieved with the use of $300 \mathrm{mg} / \mathrm{L}$ alum, while the percentage removal of dye was 83.64 with the use of $80 \mathrm{mg} \mathrm{L}^{-1} \mathrm{CaO}$ in addition to $300 \mathrm{mg} \mathrm{L}^{-1}$ of alum. Adjustment of the $\mathrm{pH}$ was not necessary in order to increase the colour removal performance as the coagulationflocculation process worked well at the original solution $\mathrm{pH}$ (5.5). Adsorption tests showed that papaya leaf can be used as a potential adsorbent for the removal of Reactive Red 3BS from aqueous solution. The pretreated effluent (effluent from the coagulationflocculation process) provided better adsorption for papaya leaf sorbent. The maximum adsorption capacity of the adsorbent was found to be more than double in the case of sorption from pretreated solution as compared with pure solution. The combined treatment method was found to be sufficient for complete removal of dye from aqueous solution. The coagulation-flocculation/adsorption process can provide a better treatment 
of wastewater contaminated with reactive dye and papaya leaf can make the process costeffective due to the availability and low price of such adsorbent.

\section{ACKNOWLEDGEMENT}

The authors would like to acknowledge the Department of Chemical Engineering and Polymer Science, Shahjalal University of Science and Technology, Bangladesh for providing support and laboratory facilities.

\section{REFERENCES}

[1] Jassal V, Shanker U, Kaith B, Shankar S. Green synthesis of potassium zinc hexacyanoferrate nanocubes and their potential application in photocatalytic degradation of organic dyes. RSC Advances. 2015;5:26141-9.

[2] Noroozi B, Sorial G, Bahrami H, Arami M. Equilibrium and kinetic adsorption study of a cationic dye by a natural adsorbent-Silkworm pupa. Journal of Hazardous Materials. 2007;139:167-74.

[3] Che Zulzikrami Azner A, Muhammad Ridwan F, Ong S-A, Siti Nurfatin Nadhirah MM, Nazzery Rosmady R. Decolourization of an azo dye in aqueous solution by ozonation in a semi-batch bubble column reactor. ScienceAsia. 2015;41:49-54.

[4] Chen X, Zhao Y, Moutinho J, Shao J, Zydney AL, He Y. Recovery of small dye molecules from aqueous solutions using charged ultrafiltration membranes. Journal of Hazardous Materials. 2015;284:58-64.

[5] Amenaghawon N, Osarumwense J, Aisien F, Olaniyan O. Preparation and investigation of the photocatalytic properties of Periwinkle shell ash for Tartrazine decolourisation. Journal of Mechanical Engineering and Sciences. 2014;7:107084.

[6] Hunge Y, Mahadik M, Kumbhar S, Mohite V, Rajpure K, Deshpande N, et al. Visible light catalysis of methyl orange using nanostructured WO 3 thin films. Ceramics International. 2016;42:789-98.

[7] Ahmad MA, Herawan SG, Yusof AA. Effect of activation time on the pinang frond based activated carbon for Remazol brilliant blue R removal. Journal of Mechanical Engineering and Sciences. 2014;7:1085-93.

[8] Subramaniam R, Ponnusamy SK. Novel adsorbent from agricultural waste (cashew NUT shell) for methylene blue dye removal: optimization by response surface methodology. Water Resources and Industry. 2015;11:64-70.

[9] Zafar MS, Tausif M, Mohsin M, Ahmad SW, Zia-ul-Haq M. Potato Starch as a Coagulant for Dye Removal from Textile Wastewater. Water, Air, \& Soil Pollution. 2015;226:1-11.

[10] Lin SH, Lin CM. Treatment of textile waste effluents by ozonation and chemical coagulation. Water Research. 1993;27:1743-8.

[11] Harrelkas F, Azizi A, Yaacoubi A, Benhammou A, Pons MN. Treatment of textile dye effluents using coagulation-flocculation coupled with membrane processes or adsorption on powdered activated carbon. Desalination. 2009;235:330-9.

[12] Lin SH, Chen ML. Purification of textile wastewater effluents by a combined Fenton process and ion exchange. Desalination. 1997;109:121-30.

[13] Furlan FR, da Silva LGdM, Morgado AF, de Souza AAU. Removal of reactive dyes from aqueous solutions using combined coagulation/flocculation and 
adsorption on activated carbon. Resources, Conservation and Recycling. 2010;54:283-90.

[14] Kristiana I, Joll C, Heitz A. Powdered activated carbon coupled with enhanced coagulation for natural organic matter removal and disinfection by-product control: Application in a Western Australian water treatment plant. Chemosphere. 2011;83:661-7.

[15] Lee J-W, Choi S-P, Thiruvenkatachari R, Shim W-G, Moon H. Submerged microfiltration membrane coupled with alum coagulation/powdered activated carbon adsorption for complete decolorization of reactive dyes. Water Research. 2006;40:435-44.

[16] Papić S, Koprivanac N, Božić AL, Meteš A. Removal of some reactive dyes from synthetic wastewater by combined $\mathrm{Al}$ (III) coagulation/carbon adsorption process. Dyes and Pigments. 2004;62:291-8.

[17] Amenaghawon N, Osarumwense J, Aisien F, Olaniyan O. Photocatalytic decolorization of Tartrazine using Periwinkle shell ash: effect of operational variables, kinetic and isotherm study. International Journal of Automotive and Mechanical Engineering. 2015;11:2555-70.

[18] Bello OS, Adegoke KA, Olaniyan AA, Abdulazeez H. Dye adsorption using biomass wastes and natural adsorbents: overview and future prospects. Desalination and Water Treatment. 2015;53:1292-315.

[19] Mohammed M, Shitu A, Ibrahim A. Removal of methylene blue using low cost adsorbent: a review. Research Journal of Chemical Sciences. 2014;4:91-102.

[20] Gowri RS, Vijayaraghavan R, Meenambigai P. Microbial degradation of reactive dyes-A Review. International Journal Current Microbiology and Applied Sciences. 2014;3:421-36.

[21] San Keskin NO, Celebioglu A, Sarioglu OF, Ozkan AD, Uyar T, Tekinay T. Removal of a reactive dye and hexavalent chromium by a reusable bacteria attached electrospun nanofibrous web. RSC Advances. 2015;5:86867-74.

[22] Mukhlish MZB, Khan MR, Bhoumick MC, Paul S. Papaya (Carica papaya L.) leaf powder: Novel adsorbent for removal of methylene blue from aqueous solution. Water, Air, \& Soil Pollution. 2012;223:4949-58.

[23] McKay G. Design models for adsorption systems in wastewater treatment. Journal of Chemical Technology and Biotechnology. 1981;31:717-31.

[24] Saukkoriipi J. Theoretical study of the hydrolysis of aluminum complexes. Acta Univ Oul, A. 2010;554.

[25] Ye C, Wang D, Shi B, Yu J, Qu J, Edwards M, et al. Alkalinity effect of coagulation with polyaluminum chlorides: Role of electrostatic patch. Colloids and Surfaces A: Physicochemical and Engineering Aspects. 2007;294:163-73.

[26] Merzouk B, Gourich B, Madani K, Vial C, Sekki A. Removal of a disperse red dye from synthetic wastewater by chemical coagulation and continuous electrocoagulation. A comparative study. Desalination. 2011;272:246-53.

[27] Weber TW, Chakravorti RK. Pore and solid diffusion models for fixed-bed adsorbers. AIChE Journal. 1974;20:228-38.

[28] Lin SH, Liu WY. Continuous treatment of textile water by ozonation and coagulation. Journal of Environmental Engineering. 1994;120:437-46.

[29] Riera-Torres M, Gutiérrez-Bouzán C, Crespi M. Combination of coagulationflocculation and nanofiltration techniques for dye removal and water reuse in textile effluents. Desalination. 2010;252:53-9. 